\title{
LA COVID-19 Y EL TURISMO EN EL PERÚ. ANÁLISIS Y PROPUESTAS ANTE UN NUEVO ESCENARIO
}

\author{
COVID-19 AND TOURISM IN PERU. \\ ANALYSIS AND PROPOSALS TOWARDS A NEW SCENARIO
}

Juan Carlos Paredes Izquierdo

Fabrizio Augusto Alberca Sialer

Angélica María Arriola Miranda

Claudia Avila Huamán

Martha Zulma Gavidia Farro

Elizabeth Sara Gómez Castillo

Ema Carmen Julca Meza

Claudia Edith Llontop Diez

José Manuel Enrique Marsano Delgado

Cristóbal Humprey Noriega Cardó

Sergio Moisés Zapata Acha

Universidad de San Martín de Porres, Perú

Aceptado: 28 de septiembre de 2020

\section{RESUMEN}

La pandemia de la COVID-19 ha generado una crisis de escala global que ha impactado en todos los quehaceres de la humanidad. Uno de los más golpeados es el turismo que, por su propia naturaleza, se enfrenta al difícil e ineludible reto de crear las condiciones para asegurar, en la medida de lo posible, la salud de los turistas, generando en ellos la confianza necesaria para un paulatino retorno a la actividad. El presente estudio aborda este tema, desde el análisis de la situación actual del turismo en el Perú hasta la presentación de un conjunto de propuestas para su reactivación, dentro del contexto global y en determinados subsectores clave.

Palabras clave: COVID-19, turismo, reactivación, patrimonio cultural, hotelería, gastronomía, Perú.

\section{ABSTRACT}

The COVID-19 pandemic has generated a global crisis that has impacted all human activities. One of the hardest hit is tourism which, by its very nature, faces the difficult and unavoidable challenge of creating the

Este es un artículo Open Access bajo la licencia Creative Commons AtribuciónNoComercial-Compartirlgual 4.0

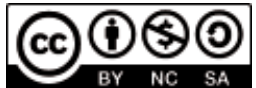


12 IUAN CARLOS PAREDES IZQUIERDO, FABRIZIO AUGUSTO ALBERCA SIALER, ANGÉLICA MARÍA ARRIOLA MIRANDA, CLAUDIA AVILA HUAMÁN MARTHA ZULMA GAVIDIA FARRO, ELIZABETH SARA GÓMEZ CASTILLO, EMA CARMEN JULCA MEZA, CLAUDIA EDITH LLONTOP DIEZ, JOSÉ MANUEL ENRIQUE MARSANO DELGADO, CRISTÓBAL HUMPREY NORIEGA CARDÓ, SERGIO MOISÉS ZAPATA ACHA

conditions to ensure, as far as possible, the health of tourists, generating in them the confidence necessary for a gradual return to activity. This article addresses this issue from an analysis of the current situation of tourism in Peru, to a set of proposals for its reactivation, both at a general level and in certain key subsectors.

Keywords: COVID-19, tourism, reactivation, cultural heritage, hospitality, gastronomy, Peru.

\section{Introducción}

El mundo viene atravesando una crisis sin precedentes ocasionada por la COVID-19, enfermedad producida por el virus SARS-CoV-2, que fue declarada pandemia por la Organización Mundial de la Salud (OMS) el día 11 de marzo de 2020, apenas 9 semanas desde su identificación. Las consecuencias del peligro, el miedo y la incertidumbre producidas por la pandemia y sus características, así como por las drásticas medidas adoptadas por los Estados para frenar su propagación, han traído como consecuencia cambios significativos en los modos de vida de prácticamente toda la humanidad (particularmente por las cuarentenas, el 'distanciamiento social' forzoso y el cierre de fronteras), y tienen efectos devastadores en la gran mayoría de actividades económicas. De estas, el turismo y las actividades vinculadas a él se encuentran entre las más afectadas, precisamente porque por su propia naturaleza, implican el desplazamiento físico de las personas.

Según cifras de la Organización Mundial del Turismo (OMT, 2020a), para abril de 2020, las restricciones de los viajes ya habían provocado a nivel mundial, una caída en las llegadas de turistas internacionales del 97\% y una consecuente pérdida de aproximadamente \$195 000 millones. En el Perú, los estimados preliminares para el año 2020 del Observatorio Turístico del Perú de la Universidad de San Martín de Porres, señalan que el aporte del sector turístico al PBI como consecuencia de la pandemia se reducirá del 3.66\% en el 2019 al 0.61\%. Si se analizan los mismos períodos en términos de soles constantes, puede apreciarse que el PIB del sector durante el año 2019 fue de S/ 19987150 000, mientras que el estimado para el año 2020 es de S/ 1665 millones. Estos estimados, sin embargo, se basan en la información con la que se cuenta actualmente, pero es imposible conocer el curso que seguirá la pandemia y todos los acontecimientos generados por ella, por tratarse de un fenómeno sobre el que no hay experiencia previa. De allí que la esperanza de un retorno a la 'normalidad' es un tema complejo.

Por un lado, no es posible saber con certeza cuándo será posible alcanzar esa normalidad. Por eso hoy en día se habla de una 'nueva normalidad', es decir, de una situación algo parecida a la que se vivía hasta el año 2019, pero en el fondo distinta, marcada principalmente por el distanciamiento social. En este momento ya resulta claro que mientras no se encuentre una vacuna o una cura para el SARS-CoV-2, no será posible regresar a la esperada normalidad. Por otro lado, es pertinente preguntarse si esa normalidad, especialmente en cuanto al modelo de consumo y de depredación de los recursos es lo deseable, o si por el contrario, es una gran oportunidad para crear un modelo nuevo y sobre todo sostenible.

No obstante, aún sin comprender del todo las características de la COVID-19 y sin saber el rumbo que tomará la pandemia, la necesidad de reiniciar lo antes posible las actividades económicas de todos los sectores, 
es comprensible. En el caso de la actividad turística, es y será necesario trabajar mucho para implementar y perfeccionar los protocolos de seguridad que reduzcan al mínimo los riesgos de contagio de los trabajadores del sector y de los turistas, no solo con el fin de preservar la salud de ambos, sino también para reestablecer la confianza de los últimos, lo que será indispensable para que las personas se aventuren a alejarse de sus lugares de residencia y se animen primero a recorrer su propio país, y luego a desplazarse al extranjero. En este último caso, también será necesario que los países adopten las medidas de seguridad necesarias para abrir sus fronteras, lo que sin duda tomará tiempo.

Aun cuando la actividad turística ha demostrado en diversas ocasiones su resiliencia y su capacidad de adaptación en diversos contextos críticos, esta crisis también ha evidenciado los problemas que el sector viene arrastrando en el Perú y que no han sido atendidos en su momento, o cuando menos, no adecuadamente. Uno de ellos es el de la informalidad, un tema presente en todas las actividades económicas en el país, y que al igual que en todas, en el caso del turismo implica la prestación de servicios de poca calidad, la situación de riesgo en la que se pueden poner la salud y la seguridad de los turistas, la competencia desleal contra las empresas formales, el descrédito del destino y la mala imagen como país. Regresar a la actividad sin enfrentar este problema, no es una opción. Otros problemas o falencias que se han hecho más visibles son el retraso como destino con relación a la innovación digital, tanto a nivel de los procesos en las empresas, como en el acopio y procesamiento de información por parte del sector público para una adecuada gestión del destino; la necesidad de que las empresas del sector cuenten con recursos humanos calificados específicamente para las tareas propias de su ámbito, y de que las instituciones educativas redefinan sus planes de estudio para formar profesionales que estén en condiciones de atender las necesidades presentes y futuras del sector, pero sobre todo que sean capaces de desenvolverse en entornos cada vez más cambiantes en los que la sanidad y la calidad deben ser las constantes; o el hecho de que conceptos como ecoeficiencia y sostenibilidad, no deben ser criterios que se adopten solo para cumplir con las normas del destino, o etiquetas con las que se necesita contar para atraer más clientes, sino formas de trabajar y de hacer empresa, que deben estar presentes en los planes, decisiones, procesos y metas, tal como lo están la rentabilidad o la eficiencia.

En este contexto, el presente estudio ofrece un análisis de la situación de la actividad turística en el Perú, así como un conjunto de propuestas para algunos de sus sectores vinculados, con el fin de contribuir a su recuperación de una manera sostenible.

\section{Análisis preliminar}

Según la data del Observatorio Turístico del Perú (OTP, 2020) de la Universidad de San Martín de Porres, durante el año 2019, el Producto Bruto Interno (PIB) de la economía peruana creció en aproximadamente $2.25 \%$, con una clara tendencia a un proceso de desaceleración, debido tanto a factores internos como externos. Si observamos las tasas de crecimiento para los períodos entre 2015 y 2019, se tienen los siguientes porcentajes: 2015: 5.8\%, 2016: 2.41\%, 2017: 2.94, 2018: 3.8\% y 2019: 2.25\%. Debe destacarse que entre los años 2017 y 2018, los precios de las materias primas fueron favorables, por lo que en la medición del PIB de esos años los precios lo favorecieron, es decir que mejoraron en una pequeña proporción los llamados términos de intercambio. Entre los factores internos que produjeron la desaceleración, pueden citarse básicamente el aumento de 
14 JUAN CARLOS PAREDES IZQUIERDO, FABRIZIO AUGUSTO ALBERCA SIALER, ANGÉLICA MARÍA ARRIOLA MIRANDA, CLAUDIA AVILA HUAMÁN MARTHA ZULMA GAVIDIA FARRO, ELIZABETH SARA GÓMEZ CASTILLO, EMA CARMEN JULCA MEZA, CLAUDIA EDITH LLONTOP DIEZ, JOSÉ MANUEL ENRIQUE MARSANO DELGADO, CRISTÓBAL HUMPREY NORIEGA CARDÓ, SERGIO MOISÉS ZAPATA ACHA

movimientos sociales antisistema, que contrajeron la inversión privada interna e internacional en más de un 20\% en el sector minero, y al pésimo comportamiento del sector pesquero para los dos últimos años. Sabido es que la inversión privada y pública, son las variables del crecimiento económico y por tanto del empleo. Se señalan estas cifras porque de acuerdo con los estudios de las cuentas satélites, elaboradas por el OTP, existe una correlación, que puede señalarse como derivada del turismo, referida a que muchos de los hombres de negocios que visitan el Perú, realizan también, directa o indirectamente, actividades turísticas. Por ello, la OMT los clasifica como visitantes o personas que realizan dicha actividad. Este grupo resulta muy importante para la generación de riqueza del sector turismo, a tal grado que, en términos simplificados, significaron un tercio de los visitantes llegados al país y que, por su perfil económico, son los que mayores recursos financieros dejan en el Perú. El segundo tercio, está conformado por los visitantes de la República de Chile, especialmente de la zona norte de dicho país, que es netamente minera. Este grupo, que muestra una mayor capacidad de compra de bienes y servicios en general en la Región Tacna, ha significado en los dos últimos años entre un millón y un millón doscientos mil visitantes. El otro tercio, está conformado por turistas propiamente dichos. Es decir, aquellos, cuya motivación para visitar el Perú fue única y exclusivamente la de realizar turismo y que en un 92.0\%, realizaron turismo histórico cultural, que es básicamente la oferta turística peruana.

En lo referente, al turismo interno peruano, son alrededor de cuatro millones de nacionales o residentes en el Perú los que realizan esta modalidad de largo aliento interno. Las principales regiones emisoras, en este rubro, son las regiones de Lima, Arequipa, Puno y La Libertad (PromPerú, 2018).

En cuanto al aporte del PIB turístico peruano para los períodos del 2015 al 2019, estas son las cifras: 2015: 3.80\%, 2016: 3.80\%, 2017: 3.80\%, 2018: 3.80\% y 2019: 3.66\%. En el año 2019, año anterior a la pandemia, se aprecia una contracción del $0.14 \%$ del PIB turístico, debido principalmente al ruido político y económico suscitado en el sector minero, su principal rubro de inversión. Este factor redujo la cantidad de hombres de negocios que visitaron el país.

Si bien la OMS y la OMT ya tenían conocimiento a fines del 2019 de la existencia del virus SARS-CoV-2 y de la enfermedad que produce (COVID-19) originada en la ciudad de Wuhan, en la República Popular China, las señales de alerta sanitarias fueron tardías, impidiendo así una contención oportuna de su propagación. A la fecha y a nivel mundial, el número de infectados y de muertos es de 32749934 y de 992 991, respectivamente (Johns Hopkins University, 2020). En el caso peruano, las cifras oficiales señalan que los infectados ya superan los 794 584, mientras que la tasa de mortalidad se encuentra en 4.03\% (Ministerio de Salud, 2020). Además de este alto costo en términos de salud y de vidas humanas, la pandemia produjo otras consecuencias, como la recesión de las economías de los países asiáticos, entre los que se encuentran algunos de los principales compradores de exportaciones peruanas. Paralelamente, la coyuntura puso al descubierto los niveles de pobreza en la que vive un porcentaje elevado de peruanos, así como la deficiente oferta de establecimientos y servicios públicos de salud de parte del país.

Los expertos consultados para la elaboración del presente estudio señalan que una vacuna contra la COVID19 que sea eficiente para el 90\% de los seres humanos, podría estar disponible, en el mejor de los casos, a fines del año 2021. De ser así, las autorizaciones de entidades como la U.S. Food and Drug Administration (FDA), 
podrían tomar hasta mediados del año 2022, momento a partir del cual recién se procedería con su distribución masiva. Esta alternativa sería más probable que la de encontrar un medicamento para ser usado por el común de los infectados, dado que el nivel de afectación de la COVID-19 es distinta en cada una de las personas.

En el caso peruano, de no contarse con una vacuna y de no manejarse adecuadamente el problema, las características de su compleja distribución geográfica y poblacional del país podrían implicar riesgos adicionales, como la posibilidad de que la enfermedad se convierta en un mal endémico. Ante este panorama, y siguiendo nuevamente a los expertos consultados, la recuperación del PIB en niveles similares al del año 2019 podría tomar no menos de tres años. En tal sentido, debe recordarse que antes de la pandemia ya se preveía una recesión mundial, por lo que en el mejor de los casos y sin efecto pandemia, el PIB del Perú no crecería en más de un $1 \%$ para el 2020, según estimaciones.

\section{Turismo y pandemia}

Con respecto a las proyecciones del turismo receptivo e interno para el año 2020, el aporte al PIB nacional no sería mayor al $0.63 \%$, y ello debido a la actividad turística de los dos meses y quince días de principios de año. Para los siguientes años (hasta el 2022), no se esperan tampoco tasas superiores a las del 0.63\%, gracias básicamente a la visita de hombres de negocios, lo cual es una razón adicional para poner en valor proyectos de inversión de capitales nacionales e internacionales, que propongan un crecimiento económico que pueda distribuirse entre las empresas y los trabajadores.

El costo, de los servicios turísticos, serán elevados en comparación con los del año 2019, como consecuencia de que el revenue de las empresas prestadoras de servicios, que conforman el producto turístico, será más elevado por las medidas sanitarias que se impondrán a todos estos servicios, en que los niveles de ocupabilidad serán menores en un promedio del 30\% con respecto a su plena ocupabilidad.

Urgirá por parte del Estado peruano, la dación de una línea de crédito a tasa de interés sumamente preferencial, con un período de gracia de 12 meses y un reembolso de capital e interés en cuotas semestrales de tres años, que permitirán acompañar a las empresas turísticas y a los sitios arqueológicos, el manejarse financieramente con un revenue alto. El Fondo de Apoyo Empresarial a las Mypes del Sector Turismo (FAE-Turismo) ascendente a 500 millones de soles, será una cifra insuficiente para la recuperación del turismo dentro del contexto de duración de la pandemia.

Otra tarea del Estado peruano, y de la ciudadanía en general, será el de reducir el altísimo nivel de informalidad de la economía peruana. El Estado peruano es uno de los países que ha destinado más recursos del erario para combatir la COVID-19, y ha tomado medidas de aislamiento social bastante severas. Sin embargo, los resultados sanitarios no son de los más retribuidos, lo que retrasará la recuperación económica y del turismo interno y receptivo, sin dejar de considerar que la reducción del grado de informalidad ayudará a una mejor distribución de los servicios sanitarios y de educación, en beneficio de la ciudadanía. En líneas generales todos los agentes económicos, en forma proporcional deberán tributar. 
16 IUAN CARLOS PAREDES IZQUIERDO, FABRIZIO AUGUSTO ALBERCA SIALER, ANGÉLICA MARÍA ARRIOLA MIRANDA, CLAUDIA AVILA HUAMÁN MARTHA ZULMA GAVIDIA FARRO, ELIZABETH SARA GÓMEZ CASTILLO, EMA CARMEN JULCA MEZA, CLAUDIA EDITH LLONTOP DIEZ, JOSÉ MANUEL ENRIQUE MARSANO DELGADO, CRISTÓBAL HUMPREY NORIEGA CARDÓ, SERGIO MOISÉS ZAPATA ACHA

A nivel regional y global, desde la declaración de la pandemia y a medida que esta fue extendiéndose por el mundo, diversos organismos multilaterales expresan su preocupación y lanzan iniciativas y estrategias para enfrentar el problema desde sus respectivos campos de acción, señalando lo imperativo de replantear la visión y la planificación del sector turístico en cada país. Por ejemplo, la Comisión Económica para América Latina y el Caribe (CEPAL, 2020), resalta la necesidad de contar con herramientas tecnológicas para enfrentar la crisis y el aislamiento; las deficiencias y desigualdades que en este punto existen en los países, especialmente en aquellos como el Perú, que cuentan con importantes expresiones del patrimonio cultural que pueden verse afectadas por esta circunstancia. En este punto, cabe resaltar la alianza establecida entre la OMT y Google, cuyo fin es acelerar la transformación digital del sector turístico.

En general, la transformación digital se ha acelerado como efecto de las cuarentenas obligatorias y del distanciamiento social impuesto por la mayoría de los gobiernos en el mundo, obligando a los Estados y a las empresas a buscar alternativas que permitan seguir trabajando y estar conectados con las actividades cotidianas; así como, permitir que la interacción de los usuarios con las empresas y los servicios se produzca con el mayor uso posible de las tecnologías digitales. Un ejemplos de ello es la proliferación del modelo del teletrabajo o home office, que requiere del establecimiento de modalidades y horarios flexibles. La incursión acelerada de la tecnología en las actividades hace necesaria su regulación en el futuro, no solo mediante normas específicas, sino mediante la modificación de las normas propias de cada actividad y sector. En el caso del turismo, el uso de la tecnología abre diversas posibilidades y oportunidades que pueden traducirse, como señala la OMT, en nuevas experiencias a un público cada vez más exigentes con la nueva normalidad, y más conectados mediante un mayor uso de redes sociales y aplicaciones informáticas.

Puesto que en su origen, la pandemia es un tema sanitario, este estará presente de ahora en adelante en prácticamente todas las actividades humanas. Por ese motivo la OMT y la OMS, vienen desarrollando acciones y resaltando la importancia fundamental de la coordinación, para enfrentar esta crisis. La propagación global del virus ha hecho colapsar los sistemas de salud en el mundo, agravando la situación económica y financiera de los países, evidenciado la fragilidad de los sistemas y generando también una perturbación social, que obliga a replantear los programas de planificación nacional y sectorial en muchos niveles, especialmente con el fin de reducir las brechas económicas, sociales y culturales existentes. Como señala la Secretaría Ejecutiva de CEPAL (2020):

La región no debe volver a su anterior modelo de desarrollo. Se necesita adoptar un nuevo grupo de políticas articuladas que incluyan un gran impulso ambiental en tres dimensiones: social (con igualdad), económica (con aprendizaje tecnológico y transformación productiva) y ambiental (con protección del medio ambiente para las actuales y futuras generaciones).

Para el caso peruano, esto implicaría la necesidad de reevaluar algunos instrumentos como el Plan Bicentenario: el Perú hacia el 2021 del Centro Nacional de Planeamiento Estratégico (CEPLAN, 2011) o la Visión del Perú al 2050 del Acuerdo Nacional (2019). 


\section{Patrimonio cultural}

La pandemia producida por la enfermedad COVID-19 también afecta los elementos del Patrimonio Cultural de la Nación (Ley n. ${ }^{2}$ 28296, 2004), en un contexto como el peruano, en el que, como en otros destinos «la relación entre turismo internacional y cultura es especialmente estrecha» (OMT, 2016, 2018).

La principal preocupación en relación con los sitios arqueológicos es la situación de extrema vulnerabilidad en la que se encuentran y cómo se han visto afectados por el escenario configurado por la pandemia. La investigación arqueológica ha estado enfocada en la recuperación de testimonios culturales de sociedades del pasado a través de una excavación rigurosa. En algunos casos, cuando los hallazgos fueron lo suficientemente singulares para generar visitas turísticas, el proyecto científico incorporó objetivos de aprovechamiento económico por medio del uso turístico, dejando expuestas parcial o íntegramente sus estructuras. En esta línea, las labores de mantenimiento, preservación y conservación fueron extremadamente costosas y, en teoría, los ingresos generados por los visitantes fueron una contribución a su financiación. ${ }^{1}$

Es así como, los sitios arqueológicos que financiaban su conservación, ya sea de forma parcial o total, con recursos generados por el boletaje turístico, han quedado desatendidos. En este contexto, la retirada de los equipos técnicos podría dar lugar a invasiones de zonas arqueológicas e incluso al tráfico ilícito de bienes culturales muebles. Un caso que refleja el impacto de la pandemia en la conservación del patrimonio es el saqueo del Sitio Arqueológico de Macatón (ubicado en la provincia de Huaral, Región Lima), luego de que se retiraron los científicos que intervenían el monumento.

En cuanto a los lugares históricos y museos, el problema principal es la interrupción de los flujos de financiamiento destinados a la preservación y conservación de sus colecciones. Se considera que podrán capear el temporal los museos que implementaron adecuadas políticas museológicas, aquellos que de manera sistemática y sostenida en el tiempo, independientemente de la pandemia, realizaron un buen trabajo de catalogación, registro y clasificación de colecciones; además de investigación.

Bajo este marco, se proponen algunas líneas de acción a los gestores culturales que intervienen en sitios con actividad turística. Se considera en primer lugar que, mediante el Ministerio de Cultura, de sus Direcciones Desconcentradas de Cultura en las regiones y en asociación estratégica con los municipios provinciales y distritales, se podrían enviar brigadas de técnicos con vocación turística a los sitios arqueológicos y lugares históricos del territorio nacional con el fin de asegurar los perímetros y garantizar medidas de protección de los sitios arqueológicos durante el estado de emergencia. Esta medida sería provisional y excepcional para frenar la invasión de terrenos, saqueo y tráfico ilícito de bienes culturales muebles. Medida, aunque factible administrativa y competencialmente, no tendría sentido desde el punto de vista económico, considerando los exiguos presupuestos que históricamente se asignan al sector cultura. Por ello, se sugiere convocar la ayuda de los organismos multilaterales y de la cooperación técnica internacional para realizar una alianza estratégica en medio de la coyuntura actual.

\footnotetext{
1 Cabe recalcar que, de los más de 20 mil sitios arqueológicos estimados en el Perú, una mínima parte presenta potencial turístico: «la situación del Perú también ilustra una importante deficiencia de la relación entre turismo y cultura, a saber, la concentración en un número relativamente reducido de exponentes del patrimonio edificado, lo que provoca que otros emplazamientos y otras formas de cultura queden en cierto modo infrautilizados» (World Economic Forum, 2013).
} 
18 JUAN CARLOS PAREDES IZQUIERDO, FABRIZIO AUGUSTO ALBERCA SIALER, ANGÉLICA MARÍA ARRIOLA MIRANDA, CLAUDIA AVILA HUAMÁN MARTHA ZULMA GAVIDIA FARRO, ELIZABETH SARA GÓMEZ CASTILLO, EMA CARMEN JULCA MEZA, CLAUDIA EDITH LLONTOP DIEZ, JOSÉ MANUEL ENRIQUE MARSANO DELGADO, CRISTÓBAL HUMPREY NORIEGA CARDÓ, SERGIO MOISÉS ZAPATA ACHA

Con relación a los museos, se considera importante proveer asistencia técnica a aquellos que así lo requieran, públicos o privados, para generar o afianzar capacidades, proveer equipos y materiales que permitan atender la conservación de sus colecciones. Para esto, una alternativa podría ser la reactivación de vínculos con museos y universidades de otros países; iniciando con aquellas que tienen presencia en Perú desde hace varias décadas.

El interés de diversas instituciones en el mundo por el estudio del pasado histórico arqueológico del Perú tiene una larga tradición, que incluye las investigaciones de Uhle en los cementerios de Ica y Chincha, financiadas por el Museo de Antropología de la Universidad de California (Menzel, 1959); los estudios de Tello financiados por la Universidad de Harvard (Lumbreras, 1972); y para mencionar ejemplos más recientes el trabajo del Proyecto Arqueológico Norte Chico PANC en los valles de Huaura, Supe, Pativilca y Fortaleza, cuyas diversas fuentes de financiamiento habrían sido canalizadas por intermedio del Museo Field de Chicago (Field Museum, 2020). Hoy, en tiempos de pandemia, ese interés puede prolongarse sobre las colecciones que yacen desprotegidas en las bodegas de los museos que, paradójicamente, estos ayudaron a completar.

Por otro lado, digitalizar y virtualizar elementos selectos de estas colecciones permitiría la supervivencia de las instituciones durante la pandemia. La generación de productos de consumo virtual complementaría el desarrollo de futuros servicios cuando termine el confinamiento. Para este fin, debe invertirse en material gráfico con la perspectiva de no limitarse a un repositorio de información online, sino que se genere un espacio virtual donde el cibernauta y la institución interactúen a lo largo de recorridos, mapas, juegos, trivias, etc. Esto podría configurarse empleando medios digitales para diseñar una propuesta creativa, no necesariamente costosa. Asimismo, se sugiere a los museos estudiar los recorridos de los visitantes para evitar aglomeraciones. Es preciso gestionar los públicos tomando en consideración las medidas de bioseguridad. En el caso de los museos, es necesario organizar y ordenar al público dentro, fuera, antes y durante la visita con horarios escalonados y aforo reducido. También, es conveniente implementar la venta anticipada y sin fecha fija de boletos online, y generar recorridos virtuales especiales para preparar y motivar al visitante. Del mismo modo, es imprescindible ser escrupulosos con las empresas que subcontraten; así como, brindar información de seguridad visible permanentemente.

En cuanto al sector artesanal, se trata de un elemento de soporte y apalancamiento de los procesos anteriores. Aún hoy en tiempos de pandemia, el stock de piezas artesanales (como souvenirs) tiene un potencial de comercialización, ya que puede ser sometido a procesos de higienización y desinfección verificables por los usuarios. Según la OMT (2020b), mediante distintas estrategias de marketing, es posible asignar a las artesanías un valor simbólico o representativo con el objetivo de lograr la conservación y el sostenimiento del destino turístico (en términos de imagen y económicos, aunque sea marginalmente). Adicionalmente, la artesanía puede presentarse a nuevos mercados como una tangibilización de la experiencia turística próxima y una especie de ticket de reserva del espacio a disfrutar en los meses venideros, involucrando lo que en marketing se denomina la promesa de venta. Esta propuesta sería alcanzable si los artesanos y los gestores adoptan procesos de innovación destinados a diversificar la oferta, privilegiando elaboraciones artesanales creativas, lúdicas, que complemente otras líneas prioritarias de actuación del Estado: 
La innovación en las pymes, las cooperativas y la economía creativa serán necesarias para la recuperación, y especialmente para el empoderamiento de las mujeres, los jóvenes y los pueblos indígenas. Sus medios de vida mejorarán con la consolidación de su acceso a los mercados y su inclusión en la cadena de valor del turismo cultural. (OMT, 2020b)

En el marco de la innovación, se propone incorporar diseños tradicionales en elementos de uso cotidiano, como en el caso de las mascarillas, que en su diseño emplearon expresiones del arte Sarhuino (originario de Ayacucho, aunque la adaptación se hace en talleres de Chorrillos, Lima). Esta propuesta representa una oportunidad segura y práctica de generación de ingresos, la cual se puede aplicar a otras expresiones artísticas como textiles, plásticas, cerámicas, de modo que encuentren un nuevo uso y así los artesanos tengan una oportunidad de generar beneficios económicos. Por otro lado, también es posible la creación de aplicaciones que difundan música, cantos e imágenes de manifestaciones inmateriales del patrimonio cultural. Estas propuestas, de cara al turismo, pueden no solo proteger, sino extender la experiencia y recuerdo del visitante una vez reiniciado el turismo.

Continuando en el plano de la artesanía, resulta necesario que los artesanos desarrollen nuevas habilidades; para lograrlo sería útil brindarles un apalancamiento a las cofradías o gremios artesanales mediante asistencia técnica en la transición hacia la nueva normalidad. Uno de los mecanismos identificados para la supervivencia de los pequeños artesanos es la aglutinación por medio de la asociatividad o el cooperativismo, ya que de manera aislada y atomizada posiblemente no logren sobrevivir.

En cuanto al patrimonio cultural inmaterial (PCI), las festividades, ferias, celebraciones o actividades populares merecen un punto aparte debido a su suspensión total por la prohibición de reuniones. Es necesario tener en cuenta en este análisis que el PCI ha logrado cada vez mayor importancia para el turismo desde una perspectiva económica (Espeso-Molinero, 2019); y que convergen en este varios actores como gestiones municipales o locales, restaurantes, artistas, artesanos, entre otros. Debido a esta crisis sanitaria, es probable que mientras no se tenga una vacuna efectiva para la enfermedad COVID-19, las festividades no podrán volver a tener grandes cantidades de público ni expresar libremente las manifestaciones culturales. Entre tanto, los eventos podrían celebrarse con participantes externos (visitantes) perfectamente identificables y con ubicaciones-posiciones específicas dentro del espacio destinado para su realización. Es de suma importancia, entonces, que cada uno de los actores sea responsable de aplicar y respetar las medidas sanitarias y de bioseguridad. En estos casos, las administraciones turísticas locales deben incorporar protocolos de bioseguridad y supervisar su aplicación. De la misma manera, los talleres, casas, o cualquier espacio donde se den manifestaciones del PCI y reciban a turistas, pueden recibir grupos pequeños manteniendo las medidas de bioseguridad previamente establecidas.

Para visibilizar y mantener activas las manifestaciones del PCI, se puede fomentar su difusión a través de los medios digitales. Los profesores de danzas tradicionales, los maestros ceramistas, los músicos y otros actores vinculados a la actividad turística pueden brindar clases virtuales con el fin de difundir y enseñar sus manifestaciones culturales tales como el idioma, los bailes, las técnicas ancestrales de orfebrería, entre otros; al mismo tiempo que generan ingresos adicionales. La iniciativa puede ser planteada por grupos organizados constituyéndose una forma de prolongar la experiencia turística de los visitantes. 
20 IUAN CARLOS PAREDES IZQUIERDO, FABRIZIO AUGUSTO ALBERCA SIALER, ANGÉLICA MARÍA ARRIOLA MIRANDA, CLAUDIA AVILA HUAMÁN MARTHA ZULMA GAVIDIA FARRO, ELIZABETH SARA GÓMEZ CASTILLO, EMA CARMEN JULCA MEZA, CLAUDIA EDITH LLONTOP DIEZ, JOSÉ MANUEL ENRIQUE MARSANO DELGADO, CRISTÓBAL HUMPREY NORIEGA CARDÓ, SERGIO MOISÉS ZAPATA ACHA

A continuación, se plantean algunas recomendaciones que aplican para las diversas categorías del patrimonio cultural:

- $\quad$ Presentar una imagen de extrema seguridad. El marketing de destinos debe preocuparse principalmente por transmitir la idea de que el destino cumple con las normas de bioseguridad (OMT, 2020b), en el marco de nuevas y fuertes exigencias de actitudes sostenibles y de seguridad sanitaria por parte de los prestadores de servicios turísticos (PromPerú, 2020).

- Estimular y movilizar flujos especialmente locales, consolidando procesos educativos y fortaleciendo capacidades de los actores locales.

- Considerar que el primer público tras la reactivación sería el interno y juvenil. Será necesario entonces conocer a estos viajeros postcovid, motivo por el cual los museos y gestores vinculados al patrimonio necesitan emprender estudios de demanda y perfiles.

- Dejar de pensar en los aspectos cuantitativos y realizar un esfuerzo para diseñar y proveer experiencias culturales valiosas. En esa línea, se debe configurar nuevos parámetros de medición en relación con la calidad de la experiencia (OMT, 2020b).

- Subsidiar, como proponen Yan et al. (s.f.), el consumo turístico mediante un bono, que puede implementarse inicialmente para turismo interno, y como aliciente para la visita de museos y consumo general en destinos.

- Desarrollar nuevas capacidades. Quienes trabajan en museos y ligados al patrimonio cultural inmaterial de uso o consumo turístico, deben desarrollar capacidades orientadas a la digitalización, virtualización y uso de tecnologías como hologramas, realidad virtual y aumentada, y otras.

Hoy más que nunca se hace indispensable la colaboración entre los sectores turismo y cultura. En este contexto, es recomendable una mayor fluidez en el intercambio de información que permita, a nivel macro, tomar mejores decisiones (OMT, 2020b).

\section{Hotelería}

Antes de la llegada del virus SARS-CoV-2, en el rubro hotelero peruano se pronosticaba un escenario positivo. Entre los años 2019 y 2021, el país tenía programado 22 proyectos hoteleros cuyo valor de inversión superaba los \$789 millones y de los cuales, más del 86\% se ubicaban en Lima (Perú tendrá 22 nuevos hoteles valorizados en US\$ 789 millones, 2020). El congelamiento del turismo obligó a paralizar las operaciones hoteleras, manteniéndose a flote en los primeros meses de aislamiento social solo los hospedajes que aceptaron brindar asilo a los repatriados, médicos y policías por una tarifa económica pagada por el Estado, programa denominado Apoyo Solidario (Ministerio de Comercio Exterior y Turismo [MINCETUR], 2020a). Esta iniciativa permitió a los peruanos repatriados y trabajadores, considerados en la primera línea de batalla frente a la pandemia, tener una cuarentena segura, evitando contagiar a su núcleo familiar.

La expansión desbordante del virus forzó al sector hotelero a reaccionar con sentido de urgencia y cambiar de un estado transitorio de incertidumbre a un escenario guiado por acciones de prevención y adaptación. Con 
la presentación de los nuevos protocolos de sanidad, MINCETUR (2020b, 2020c) busca reanudar las actividades en el rubro, impulsando la alineación de estándares en todos los hoteles debidamente categorizados y en los no categorizados ni clasificados, tomando en consideración prácticas sostenibles e incentivando a las empresas a realizar capacitaciones internas basadas en la seguridad y el bienestar de los colaboradores y huéspedes. Las etapas de respuesta de los hoteles para hacer frente a la pandemia se describen a continuación:

- $\quad$ Primera etapa: cancelaciones y modificaciones de reservas en todas las áreas.

- Segunda etapa: días de cuarentena para los huéspedes de tránsito varados por el cierre de fronteras.

- Tercera etapa: hospedaje solidario a repatriados, personal médico y policías.

- Cuarta etapa: renta de habitaciones por estadías prolongadas, enfocándose en el público local que debe pasar la cuarentena aislado del núcleo familiar, como los trabajadores de la industria minera, pesquera y todo profesional expuesto al riesgo de contagio por sus actividades. Para el público empresarial se adecuaron habitaciones para usarlas como oficinas.

- Quinta etapa: restablecimiento del área de alimentos y bebidas en los servicios de room service (cliente interno) y delivery/take away (cliente externo).

- Sexta etapa: ingreso de reservas para hospedajes ubicados en zonas de campo y playa, y bloqueos tentativos de habitaciones para futuras reservas internacionales.

- Séptima etapa: rehabilitación del área de spa (gimnasio, piscina, peluquería).

- Octava etapa: activación del área de eventos (sociales y corporativos).

Después de la acción tomada en la primera etapa, los hoteles empezaron a identificar los puntos de mayor manipulación en sus recintos. Para protegerse de estos potenciales focos de contagio, los hospedajes realizaron dos compras inmediatas: equipos de protección personal (EPP) y máquinas para la eliminación de bacterias y agentes contaminantes. Las cadenas internacionales, especialmente las tres más grandes de la industria por su número de propiedades y habitaciones (Marriot Internacional, Hilton Hotels \& Resort, e InterContinental Hotels Group) al ser referentes en el medio hotelero, rápidamente adoptaron el compromiso y la responsabilidad de incorporar en sus operaciones nueva tecnología desinfectante que permita asegurar espacios protegidos de COVID19 validando su seguridad sanitaria con sellos covid-free. Entre la tecnología usada para prevenir y mitigar la propagación del virus se encuentran los pulverizadores electrostáticos, las máquinas generadoras de ozono y la luz ultravioleta (Asociación española de gobernantas de hotel y otras entidades [ASEGO], 2020).

Por otro lado, incentivaron el uso de la tecnología digital, biométrica, IoT, AI, Blockchain, entre otras, que consienten la automatización en procedimientos tradicionalmente cumplidos por el colaborador y ahora resueltos por el huésped, perfeccionando estos procesos, para que el cliente realice diferentes actividades sin necesitar de un contacto directo con el trabajador (Ahmed, 2017). 
22 JUAN CARLOS PAREDES IZQUIERDO, FABRIZIO AUGUSTO ALBERCA SIALER, ANGÉLICA MARÍA ARRIOLA MIRANDA, CLAUDIA AVILA HUAMÁN MARTHA ZULMA GAVIDIA FARRO, ELIZABETH SARA GÓMEZ CASTILLO, EMA CARMEN JULCA MEZA, CLAUDIA EDITH LLONTOP DIEZ, JOSÉ MANUEL ENRIQUE MARSANO DELGADO, CRISTÓBAL HUMPREY NORIEGA CARDÓ, SERGIO MOISÉS ZAPATA ACHA

Tabla 1

Aportes de las tres cadenas hoteleras más grandes del mundo, sus alianzas estratégicas frente al SARS-CoV-2 y su participación en el mercado peruano

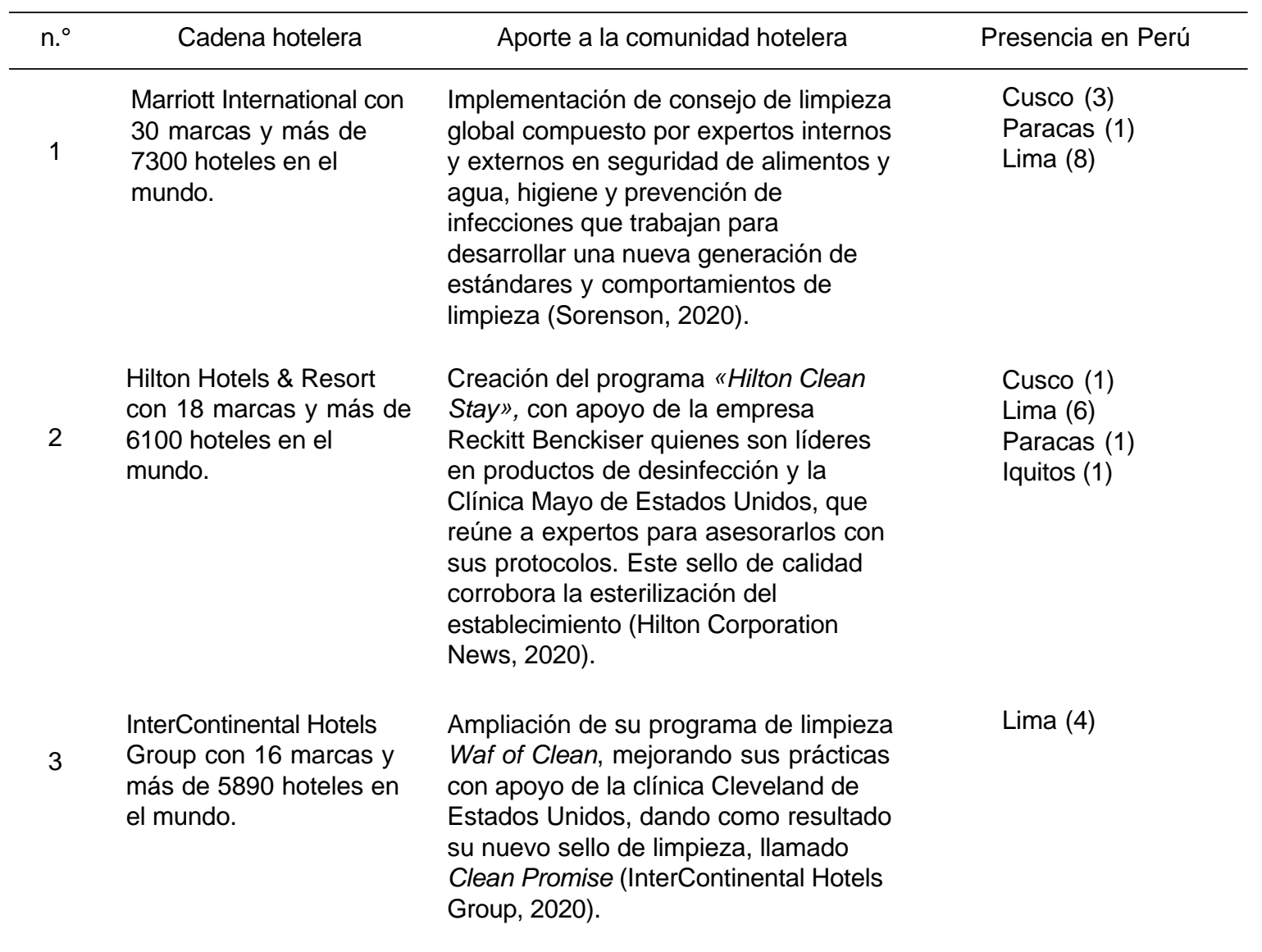

Nota. Elaboración propia.

Para complementar sus esfuerzos en la búsqueda de la bioseguridad, estas tres cadenas hoteleras han realizado alianzas estratégicas con especialistas de la salud para generar protocolos de limpieza hotelera a nivel mundial, buscando compartir sus conocimientos con toda comunidad, empoderando sus marcas y estableciendo los nuevos procedimientos.

Adicionalmente, sus programas de fidelidad conocidos como IHG Rewards Club, Hilton Honors y Marriott Bonvoy, están extendiendo los beneficios de sus socios por un año, invitándolos además a convertir sus puntos en una donación equivalente en efectivo, para apoyar a poblaciones vulnerables afectadas por el virus; trascendiendo así, el compromiso empresarial de estas grandes cadenas, con el ámbito social.

Con respecto al área de alimentos y bebidas de los hoteles, la reintegración se está realizando de manera gradual sobre la base de dos tipos de servicios: room service y delivery/take and go. Al brindar alimentos a los repatriados, el área creó nuevos protocolos de higiene, empaquetado y entrega, incrementando su movimiento y 
posicionándose como el tipo de atención preferida por los futuros huéspedes, al ser la mejor alternativa para evitar el contacto con otros comensales. En relación con las estrategias adoptadas en el servicio de delivery/take and go, estas se basan en la nueva tendencia de pedido por medio de las plataformas digitales. Asimismo, el servicio buffet se ha reinventado llevando la experiencia gastronómica a la casa de los clientes con una selección parcial de sus platos. Los restauranteros, por su lado, han decidido reducir su carta a los best seller del restaurante, para ofrecer platos fáciles y rápidos de hacer, que puedan conservarse frescos y en buenas condiciones. Con relación a la atención directa en los restaurantes, se redujo los aforos y se puso en marcha protocolos para evitar el contacto con meseros, como la implementación de QR en las mesas (Hotel Perú News, 2020).

En la sexta etapa, los hoteles buscarán promocionar sus establecimientos fuera de Lima, que se encuentran ubicados en regiones con atractivos ancla para la visita local (MINCETUR, 2020d).

Tanto la séptima como la octava etapa son las actividades consideradas con mayor riesgo de contagio en la lista de servicios ofrecidos por los hoteles, es por ello que serán las últimas en reestablecerse. En cuanto a los spas si bien la actividad física reduce el riesgo de enfermarse, el uso de las máquinas del gimnasio, el sauna, la piscina, entre otras instalaciones, son consideradas como posibles grandes focos de contagio (ABC, 2020). La última etapa de activación se realizará en el departamento de eventos, en primera instancia esta área se limitará a la demanda interna del país y será necesaria la creación de nuevos modelos de encuentros entre personas como la estrategia llamada 'eventos híbridos', donde una parte de los asistentes está físicamente y otra parte en forma virtual, así los aforos serán mínimos y los armados de los salones respetarán el distanciamiento social permitido (International Congress and Convention Association [ICCA], 2020).

La hotelería tiene la promesa de renacer, pero con un enfoque diferente. La propuesta que se brinda, busca darle ese nuevo giro al modelo de negocio hotelero tradicional. Hay que considerar que así como se han removido puestos y servicios, también aumentan otras exigencias, por ello muchos hoteles tendrán que enfrentar un sobrecosto por implementación de maquinarias, protocolos, tecnología nueva; siendo necesario optimar recursos, obligándolos a bloquear habitaciones temporalmente para reducir costos fijos y no perder así liquidez y rentabilidad.

Inicialmente, el hotelero debe enfocarse en su cliente corporativo ya que será el primero en moverse, este tipo de huésped se caracteriza por tener estadías largas, con agendas ocupadas, en donde la frase el tiempo es dinero es un estilo de vida. A este tipo de cliente se le puede ofrecer una habitación con un concepto de apart hotel, donde tenga un pequeño kitchenette, un comedor y programas por anticipado para su alimentación diaria, incentivando así la atención «self service». Dependiendo del tipo de hospedaje (hotel, resort, boutique) este concepto podría ser adecuado en sus instalaciones y ofrecer así estancias prolongadas, asegurando la permanencia del huésped y, por ende, el uso de una habitación que al final del día es un producto perecedero. Es posible además, plantear la adopción de tiempo compartido, que en esencia es el pago adelantado del hospedaje para adquirir una habitación por temporada. Por otro lado, los hospedajes económicos y las viviendas con fines turísticos, deben modificar su factor de éxito basado en la economía compartida, donde predominaba el espíritu de compartir una habitación, ahora pueden ofrecer espacios comunes que respeten el distanciamiento social con habitaciones individuales. 
24 IUAN CARLOS PAREDES IZQUIERDO, FABRIZIO AUGUSTO ALBERCA SIALER, ANGÉLICA MARÍA ARRIOLA MIRANDA, CLAUDIA AVILA HUAMÁN MARTHA ZULMA GAVIDIA FARRO, ELIZABETH SARA GÓMEZ CASTILLO, EMA CARMEN JULCA MEZA, CLAUDIA EDITH LLONTOP DIEZ, JOSÉ MANUEL ENRIQUE MARSANO DELGADO, CRISTÓBAL HUMPREY NORIEGA CARDÓ, SERGIO MOISÉS ZAPATA ACHA

Dentro de las alternativas de inversión menos costosas, están los pediluvios desinfectantes que se colocan fuera de cada habitación. Otra estrategia que podría evitar la contaminación externa traída en el calzado de los huéspedes, es la adaptación de una tradición asiática donde existen espacios llamados genkan que son compartimientos al lado de la entrada de la habitación donde se dejan los zapatos usados para ponerse y utilizar en la habitaciones unas pantuflas ligeras. Los hoteles también podrán implementar en sus servicios de limpieza, la desinfección de calzado a pedido del cliente.

De acuerdo con los expertos de la industria, la reactivación general de la hotelería podría extenderse hacia el 2021. Actualmente nuestra oferta hotelera local viene impactando de forma positiva los niveles de ocupación (UNWTO, 2020) por lo cual, el pronóstico para nuestra región luce un poco más alentador con relación a otros países de Sudamérica. Esta predicción dependerá del comportamiento del virus y de la auténtica conciencia de los ciudadanos en tomar medidas protectoras para evitar el contagio. El reto que sí puede controlar el sector, es trabajar en la reconquista del huésped para recuperar su confianza, siendo flexibles y creativos con las estrategias, adaptándose a las nuevas necesidades y estilos de vida. Para restablecer esta alianza, se debe aprovechar cada oportunidad en capacitar al personal y en compartir con la sociedad todos los esfuerzos de adaptación y prevención ejercidos por los hoteles, siendo así, la asesoría de expertos de salud, los protocolos rigurosos de sanidad, los sellos de calidad y la tecnología innovadora, las mayores herramientas diferenciadoras. En cierta medida, más que un esfuerzo individual de hoteles pequeños o grandes, se debe realizar una cohesión de impacto que reúna a todos los involucrados para compartir experiencias y posibles soluciones en el área hotelera.

\section{Gastronomía}

Por sus características, la crisis ocasionada por la pandemia de la enfermedad COVID-19 ha golpeado drásticamente al sector gastronómico peruano, haciendo necesaria la adopción de nuevas medidas tanto en aspectos sanitarios como económicos; además de cambios en el comportamiento social, en la gestión y la planificación que se deben trabajar con la finalidad de reactivar este sector clave para el desarrollo del turismo y la hotelería.

Para analizar la coyuntura del sector gastronómico actual, es necesario poner en contexto los hechos más relevantes de los años previos.

En cuanto al megaevento Mistura, se dejó de realizar el año 2018, sin embargo, ya mostraba síntomas de 'agotamiento' desde años anteriores, pues el volumen del evento en términos de asistencia no bastaba para renovar la masiva convocatoria, no llegando además a concretarse una de las principales metas del sector: la justa y recíproca unión entre productores y cocineros (al menos no en la medida que proclamaba el discurso mediático general). Asimismo, la Asociación Peruana de Gastronomía (APEGA), ente representante del sector gastronómico en el Perú, terminó por desintegrarse mucho antes de la llegada del nuevo coronavirus, entrando a esta crisis sin representatividad (Matta, 2019).

La llegada de la pandemia impulsa al sector gastronómico a replantear el modelo y a efectuar necesarias modificaciones. El sector gastronómico peruano, es uno de los principales impulsores de la economía, por ello es importante prestarle atención: 
Da empleo a, por lo menos, 992 mil peruanos, entre agricultores, proveedores, transportistas, cocineros, personal administrativo y de servicio, es decir, todo el elemento humano que se encuentra detrás del así llamado boom de la gastronomía peruana, que se vive tanto en nuestro país como en el extranjero. (Hay que salvar la gastronomía, 2020, párr. 2)

Esa debe ser su finalidad y respuesta. A continuación, se plantean algunas propuestas específicas para hacer frente a la crisis del sector generada por el contexto actual.

\section{Propuestas frente a la crisis de la pandemia, para el sector gastronómico}

- Como primera acción de reactivación del sector gastronómico, se estableció el servicio del delivery. Sin embargo, sería conveniente que el Ministerio de Trabajo y Promoción del Empleo (MTPE) en coordinación con el Ministerio de Salud (MINSA), planifique y establezca, como parte del protocolo, el control de descarte (de forma periódica) para las personas responsables en la repartición de alimentos a domicilio con el fin de cumplir con todas las normas de sanidad.

- Según la opinión de los chefs entrevistados, se tiene que desarrollar otras alternativas en el largo plazo para sostener la actividad restaurantera. Sugieren que se practique una trazabilidad en los alimentos, que consiste en llevar un control en todos los eslabones de la cadena productiva, desde la cosecha, beneficio, extracción o captura, procesamiento y comercialización hasta la entrega al consumidor, asegurando la calidad y bioseguridad alimentaria (European Food Safety Autority [EFSA], 2020).

- Desarrollar una propuesta tecnológica para inactivar la letalidad del virus en alimentos terminados. Según estudios científicos del Instituto de Investigación y Tecnología Agroalimentarias (IRTA, 2020) de Cataluña, «el 99,99 \% de la carga vírica de SARS-CoV-2 en espacios cerrados y superficies se inactivaría si estos se someten a una temperatura de $56{ }^{\circ} \mathrm{C}$ durante 52 minutos o bien a $65{ }^{\circ} \mathrm{C}$ durante 7,5 minutos» (u otros parámetros equivalentes, dependiendo de la cinética de destrucción térmica). Ante la eventualidad de una contaminación posterior, mediante este proceso se logra la inocuidad de los alimentos preparados durante el envasado, transporte y entrega (delivery), generando así mayor confianza entre los consumidores.

- Los restaurantes tendrían que reducir el número de sus preparaciones, optando por propuestas más prácticas y económicas además de revalorar los insumos peruanos.

- $\quad$ En el mediano plazo se realizará el cumplimiento del protocolo para la atención en salón en los restaurantes y a largo plazo será un nuevo estilo de experiencia gastronómica que implicará cambios en los hábitos alimenticios y en el comportamiento social en restaurantes, que incluso contemplen pasar a un modelo donde se ofrezca dos comidas diarias balanceadas nutricionalmente. El catering no puede operar ya que no se realizarán eventos masivos. Los comedores populares trabajarán a puertas cerradas con servicio solo para llevar preparando comidas saludables que favorezcan la nutrición. 
26 IUAN CARLOS PAREDES IZQUIERDO, FABRIZIO AUGUSTO ALBERCA SIALER, ANGÉLICA MARÍA ARRIOLA MIRANDA, CLAUDIA AVILA HUAMÁN MARTHA ZULMA GAVIDIA FARRO, ELIZABETH SARA GÓMEZ CASTILLO, EMA CARMEN JULCA MEZA, CLAUDIA EDITH LLONTOP DIEZ, JOSÉ MANUEL ENRIQUE MARSANO DELGADO, CRISTÓBAL HUMPREY NORIEGA CARDÓ, SERGIO MOISÉS ZAPATA ACHA

\section{Propuestas en relación con el patrimonio gastronómico}

- Poner énfasis en el turismo gastronómico interno. Actualmente, existe consenso general en indicar mirar y entender al cliente local, puesto que no tienen las mismas preferencias y gustos que el turista extranjero. En consecuencia, habrá que cambiar, adaptando la oferta a los costos y necesidades del turista nacional. En esa misma línea, las personas entrevistadas señalaron como prioridad el abastecimiento de insumos mediante la compra a los productores nacionales y un menor uso de productos importados en las recetas, fomentando así la expresión de la biodiversidad de regiones.

- Fomentar la cultura gastronómica de las cocinas regionales preguntándonos ¿cómo hacer para que recuperen su cocina?, y ¿cómo poner en valor la cadena gastronómica? Lo que se requiere es empoderar las regiones, como lo viene haciendo la Universidad de San Martín de Porres, impulsado las investigaciones en cocinas regionales.

- Un punto importante a considerar es la promoción virtual del patrimonio gastronómico peruano. Hacer una mayor incidencia en el turismo interno a lo largo de nuevas rutas gastronómicas y alimentarias, rutas mixtas, con destinos cortos, seguros y familiares.

\section{Propuestas a las políticas de Estado}

- $\quad$ Frente a la crisis sanitaria actual, resulta necesario y urgente legislar y normalizar el inexistente rubro de los negocios de pescadería, facilitando la compra directa al pescador y piscicultor para abastecer con pescado fresco y congelado a los hogares y restaurantes, mejorando así la cadena de comercialización.

- Los pequeños negocios de emprendimientos relacionados con la gastronomía peruana -desde productores hasta los que ofertan comida preparada- pueden recibir asistencia técnica para facilitar los trámites de formalización y estar aptos para recibir beneficios crediticios. Se sugiere, como primer paso, realizar un inventario o censo de huariques, puestos de venta de comida en mercados, pequeños restaurantes y negocios de cocina con miras a facilitar su formalización.

- Para reactivar el sector gastronómico, es preciso revisar y analizar las políticas públicas que alivien económicamente a los negocios formales, sobre todo, con relación a los impuestos y otros costos adicionales.

\section{Propuesta de proyectos}

- Educar al consumidor sobre la importancia y el respeto a los protocolos de salud y bioseguridad.

- Desarrollar recetarios regionales online, con énfasis en la biodiversidad de cada región. Recetas prácticas, económicas con énfasis en aspectos nutricionales e inmunológicos que refuercen la salud de las personas; enfocados en los diferentes intereses del público: infantes, madres gestantes, adultos mayores, etc.

- Diseñar y ejecutar el proyecto Museo Virtual de la Gastronomía Peruana. La vasta experiencia en la investigación y edición de libros sobre gastronomía peruana por parte de la Facultad de Ciencias de la 
Comunicación, Turismo y Psicología, así como de la Escuela Profesional de Turismo y Hotelería de la Universidad de San Martín de Porres, permite sustentar la creación del mencionado museo. La modalidad virtual provee espacios que proporcionan el entorno para la construcción del proceso de identificación cultural, permitiendo enfatizar en el discurso. La puesta en marcha de este proyecto es importante y necesaria pensando en el bienestar educativo y social frente a la crisis (Alemán, 2017).

\section{Conclusiones}

El Perú y todos los países verán una significativa contracción en su PIB para el presente año; esto, el posterior crecimiento o no de las economías y el desarrollo de la pandemia son factores que incidirán en una mayor o una menor demanda turística. El escenario resultante constituirá el inicio de una nueva etapa del desarrollo de la actividad turística, es decir que muchos de los cambios que se están produciendo o que se producirán, no son temporales, sino que muy probablemente resultarán en una 'nueva normalidad'. Esta nueva normalidad tampoco será permanente, ya que las condiciones podrían seguir transformándose en el futuro, de manera que la rápida adaptabilidad al cambio será indispensable.

Sin duda, los retos más grandes son reestablecer la confianza de los turistas; promocionar el destino con el fin de mantener una presencia constante en las mentes de las personas, la creación de mecanismos para la reducción de la informalidad en el sector; el diseño de nuevos productos turísticos que respondan a las nuevas demandas; la creación e implementación de herramientas para la recolección y procesamiento inmediato de datos útiles para la gestión del destino y la toma de decisiones de las instituciones del sector público, pero también a disposición de las empresas, de forma que puedan gestionarse de manera óptima con información oportuna y veraz; campo en el cual la academia puede contribuir de manera muy relevante por medio de la investigación.

Desde el sector privado, las empresas, particularmente las medianas y pequeñas, necesitan colocar la sostenibilidad en el centro de sus operaciones y de todas sus iniciativas; reforzar la formación de sus recursos humanos en temas relacionados a las competencias digitales, la sanidad y el servicio al cliente; así como crear equipos de trabajo centrados en las personas, donde la norma incluya comunicación, flexibilidad y rapidez en la toma de decisiones.

En este nuevo escenario -siguiendo las recomendaciones de los organismos internacionales- la comunicación, la coordinación y el trabajo articulado entre las entidades públicas, las empresas y la comunidad son indispensables con el fin de formular políticas, estrategias y planes de acción que permitan corregir los errores del pasado, y en su momento, dar paso a una recuperación ordenada, informada y sensible del sector. Un auténtico desarrollo turístico sostenible. 
28 JUAN CARLOS PAREDES IZQUIERDO, FABRIZIO AUGUSTO ALBERCA SIALER, ANGÉLICA MARÍA ARRIOLA MIRANDA, CLAUDIA AVILA HUAMÁN, MARTHA ZULMA GAVIDIA FARRO, ELIZABETH SARA GÓMEZ CASTILLO, EMA CARMEN JULCA MEZA, CLAUDIA EDITH LLONTOP DIEZ, JOSÉ MANUEL ENRIQUE MARSANO DELGADO, CRISTÓBAL HUMPREY NORIEGA CARDÓ, SERGIO MOISÉS ZAPATA ACHA

\section{Agradecimientos}

Los autores expresan su reconocimiento y gratitud a los profesionales que contribuyeron, en momentos muy difíciles, con su tiempo y sus valiosos conocimientos en este estudio que dio lugar al presente artículo. Ellos son Marisol Acosta, Javier Alcalde, Isabel Álvarez Novoa, Waldin Duran, Gabriela Fiorini de Perret, Gabriela Gadea, César García Calderón, Luis Guillermo Lumbreras, Luis Santiago Marsano Obando, Alberto Martorell, Eliana Núñez, Alejandro Reyes Hurtado, Sergio Rivas, Pedro Miguel Schiaffino, Bruno Seminario De Marzi.

\section{Referencias}

ABC. (2020). Gyms are sweaty, Are they risky? https://www.abc.net.au/radio/programs/coronacast/gyms-are-sweaty-are-they-risky/ 12044196

Ahmed, M. (6 de julio de 2017). Hilton opens door to using mobile phone as hotel key. Financial Times. https://www.ft.com/content/ 28455880-6232-11e7-8814-0ac7eb84e5f1

Alemán, A. (2017). Los museos virtuales en el Perú como entornos en el proceso de construcción de la identidad cultural: caso museo virtual de gastronomía peruana [Tesis doctoral, Universidad de San Martín de Porres]. http:// www.repositorioacademico.usmp.edu.pe/bitstream/handle/usmp/2876/ALEMAN_CA.pdf?sequence=1\&isAllowed=y

Asociación española de gobernantas de hotel y otras entidades (ASEGO). (2020). Reclutamiento de información para actuación en la revisión de procedimiento posterior a covid-19 según ASEGO. https://tecnohotelnews.com/wp-content/uploads/2020/05/ Reclutamiento-de-informaci\%C3\%B3n-para-actuaci\%C3\%B3n-en-la-revisi\%C3\%B3n-de-procedimientos-posterior-a-COVID19seg\%C3\%BAn-ASEGO-1.pdf

Centro Nacional de Planeamiento Estratégico (CEPLAN). (2011). Plan Bicentenario: el Perú hacia el 2021. https://www.ceplan.gob.pe/ documentos_plan-bicentenario-el-peru-hacia-el-2021/

Comisión Económica para América Latina y el Caribe (CEPAL). (2020). Para reconstruir mejor tras el COVID-19 es necesario hacerlo con igualdad y sostenibilidad. https://www.cepal.org/es/comunicados/reconstruir-mejor-tras-covid-19-es-necesario-hacerloigualdad-sostenibilidad-cepal

Espeso-Molinero, P. (2019). Tendencias del turismo cultural. PASOS Revista de turismo y patrimonio cultural, 6(17), 1101-1112.

European Food Safety Autority (EFSA). (2020). Coronavirus: no hay pruebas de que los alimentos sean una fuente o una vía de transmisión del virus. https://www.efsa.europa.eu/es/news/coronavirus-no-evidence-food-source-or-transmission-route.

Field Museum. (2020). Proyecto Arqueológico Norte Chico. https://www.fieldmuseum.org/science/research/area/cultural-heritage/culturalheritage-surveys/proyecto-arqueologico-norte

Hay que salvar la gastronomía. (8 de abril de 2020). Perú 21 [Editorial]. https://peru21.pe/opinion/hay-que-salvar-la-gastronomia-noticia/

Hotel Perú News (Productor). (junio de 2020). Nuevos servicios de delivery y aplicación de protocolos en restaurantes [6. ${ }^{\text {a }}$ videoconferencia]. https://www.youtube.com/watch?v=wBVD0DQQs8k

Instituto de Investigación y Tecnología Agroalimentarias (IRTA). (25 de mayo de 2020). Estos son la temperatura y el tiempo necesarios para eliminar el coronavirus en espacios cerrados. Sinc Tecnología. https:/www.agenciasinc.es/Noticias/Estos-son-la-temperaturay-el-tiempo-necesarios-para-eliminar-el-coronavirus-en-espacios-cerrados

International Congress and Convention Association (ICCA). (2020). Good practice guidance: Addressing COVID-19 Requirements for Re-Opening Business Events. https://www.iccaworld.org/covid-19/

Johns Hopkins University. (2020). Coronavirus Resource Center. https://coronavirus.jhu.edu/

Ley n. ${ }^{\circ}$ 28296. (2004). Ley General del Patrimonio Cultural de la Nación. 
Lumbreras, L. (1972). Julio C. Tello, 25 años después. Arqueología y Sociedad, 7(8), 7-12.

Matta, R. (2019). El boom gastronómico peruano: entre moda y promesas incumplidas. Entrevista a Isabel Álvarez. Anthropology of food, 14. https://doi.org/10.4000/aof.9987

Menzel, D. (1959). The Inca Occupation of the South Coast of Perú. Southwestern Journal of Anthropology, 15(2), 125-142.

Ministerio de Comercio Exterior y Turismo (MINCETUR). (2020a). Apoyo solidario: El Estado peruano y más de 60 hoteles se unen para brindar cuarentena preventiva a los repatriados. https:/www.gob.pe/institucion/mincetur/noticias/125579-apoyo-solidarioel-estado-peruano-y-mas-de-60-hoteles-se-unen-para-brindar-cuarentena-preventiva-a-los-repatriados

Ministerio de Comercio Exterior y Turismo (MINCETUR). (2020b). Protocolo sanitario sectorial ante el COVID19 para hoteles categorizados. https:/consultasenlinea.mincetur.gob.pe/DocumentosNormativos/Publico/Imagen.aspx?ITEM=366149\&fbclid =IwAR2EcacWjFqwm6Qa463Asv4yPPsv8N7puL_xgLAcz0mzFJ6KhcVtaa028xQ

Ministerio de Comercio Exterior y Turismo (MINCETUR). (2020c). Protocolo sanitario sectorial ante el covid-19 para hostales categorizados y establecimientos de hospedaje no clasificados ni categorizados con constancia de declaración jurada. https:/ /www.gob.pe/institucion/mincetur/normas-legales/826793-122-2020-mincetur

Ministerio de Comercio Exterior y Turismo (MINCETUR). (2020d). Ministra Barrios: Paracas será un atractivo «ancla» en una próxima reactivación del turismo interno. https://www.gob.pe/institucion/mincetur/noticias/302098-ministra-barrios-paracas-sera-unatractivo-ancla-en-una-proxima-reactivacion-del-turismo-interno

Ministerio de Salud (MINSA). (2020). Sala Situacional COVID-19 Perú. https://covid19.minsa.gob.pe/sala_situacional.asp

Observatorio Turístico del Perú. (2020). Universidad de San Martín de Porres. http://www.observatorioturisticodelperu.com/

Organización Mundial de la Salud (OMS). (2020). Los nombres de la enfermedad por coronavirus (COVID-19) y del virus que la causa. https://www.who.int/es/emergencies/diseases/novel-coronavirus-2019/technical-guidance/naming-the-coronavirus-disease-(covid2019)-and-the-virus-that-causes-it

Organización Mundial del Turismo (OMT). (2016). Alianza entre turismo y cultura en el Perú. Modelos de colaboración entre turismo, cultura y comunidad. https://www.e-unwto.org/doi/pdf/10.18111/9789284417575

Organización Mundial del Turismo (OMT). (2018). Tourism and Culture Synergies.

Organización Mundial del Turismo (OMT). (2020a). Los nuevos datos muestran el impacto de COVID-19 en el turismo, mientras la OMT pide un reinicio responsable del sector. https://www.unwto.org/es/news/los-nuevos-datos-muestran-el-impacto-de-covid-19en-el-turismo

Organización Mundial del Turismo (OMT). (2020b). Global Guidelines to Restart Tourism. https://webunwto.s3.eu-west1.amazonaws.com/s3fs-public/2020-05/UNWTO-Global-Guidelines-to-Restart-Tourism.pdf

Perú tendrá 22 nuevos hoteles valorizados en US\$ 789 millones. (10 de julio de 2019). Gestión [Empresas]. https://gestion.pe/economia/ empresas/peru-tendra-22-nuevos-hoteles-valorizados-us-789-millones-272763-noticia/

PromPerú. (2018). Perfil del Vacacionista Nacional. Turismo Innova. https://www.promperu.gob.pe/TurismoIN/sitio/ VisorDocumentos?titulo=Perfil\%20del\%20Vacacionista\%20Nacional\%202018\&url= /Uploads/perfiles_vacac_nac/1040/ Perfil\%20del\%20Vacacionista \%20Nacional\%202018.pdf\&nombObjeto= PerfVacacionistaNac\&back=/TurismoIN/sitio/ PerfVacacionistaNac\&issuuid=

PromPerú. (abril de 2020). COVID-19: descubre 6 futuras tendencias mundiales de consumo. Turismo in, investiga, innova, 69. https:/ /www.promperu.gob.pe/turismoin/Boletines/2020/abr/index.html

Sorenson, A. (6 de mayo de 2020 ). Marriott's Commitment to Cleanliness. https://www.linkedin.com/pulse/marriotts-commitmentcleanliness-arne-sorenson/

UNWTO. (2020, 5 de mayo). El impacto del COVID-19 en el turismo-American Insights [Live Webinar]. Youtube. https:// www.youtube.com/watch?v=oiHGz91mPN4

World Economic Forum. (2013). The Peru Travel and Tourism Competitiveness (Report). WEF, Ginebra.

Yang, Y., Zhang, H. y Chen, X. (s.f.). Coronavirus pandemic and tourism: Dynamic stochastic general equilibrium modeling of infectious disease outbreak. Annals of Tourism Research [Artículo en prensa]. 
30 IUAN CARLOS PAREDES IZQUIERDO, FABRIZIO AUGUSTO ALBERCA SIALER, ANGÉLICA MARÍA ARRIOLA MIRANDA, CLAUDIA AVILA HUAMÁN MARTHA ZULMA GAVIDIA FARRO, ELIZABETH SARA GÓMEZ CASTILLO, EMA CARMEN JULCA MEZA, CLAUDIA EDITH LLONTOP DIEZ, JOSÉ MANUEL ENRIQUE MARSANO DELGADO, CRISTÓBAL HUMPREY NORIEGA CARDÓ, SERGIO MOISÉS ZAPATA ACHA

Juan Carlos Paredes Izquierdo

Director del Instituto de Investigación de la Escuela Profesional de Turismo y Hotelería de la Universidad de San Martín de Porres. Doctor en Turismo por la USMP (Perú). ORCID: https://orcid.org/0000-0002-8375-614X

Fabrizio Augusto Alberca Sialer

Magister en Gestión Cultural, Patrimono y Turismo por la Universidad de San Martín de Porres (Perú). Docente e investigador de la Escuela Profesional de Turismo y Hotelería de la USMP.

ORCID: https://orcid.org/0000-0001-6330-0762

Angélica María Arriola Miranda

Doctora en Turismo por la Universidad de San Martín de Porres (Perú). Docente e investigadora de la Escuela Profesional de Turismo y Hotelería de la USMP.

ORCID: https://orcid.org/0000-0002-9495-327X

Claudia Avila Huamán

Magister en Dirección Estratégica y Liderazgo por la Escuela de Negocios Centrum Católica (Perú). Docente e investigadora de la Escuela Profesional de Turismo y Hotelería de la Universidad de San Martín de Porres.

ORCID: https://orcid.org/0000-0002-3782-0497

Martha Zulma Gavidia Farro

Magister en Gestión Cultural, Patrimono y Turismo por la Universidad de San Martín de Porres (Perú). Docente e investigadora de la Escuela Profesional de Turismo y Hotelería de la USMP.

ORCID: https://orcid.org/0000-0002-7651-7247

Elizabeth Sara Gómez Castillo

Magister en Ciencias Gastronómicas por la Universidad de San Martín de Porres (Perú). Docente e investigadora de la Escuela Profesional de Turismo y Hotelería de la USMP.

ORCID: https://orcid.org/0000-0001-6108-965X

Ema Carmen Julca Meza

Doctora en Psicología Organizacional-Sostenibilidad por la Universidad de Salamanca (España). Docente e investigadora de la Escuela Profesional de Turismo y Hotelería de la Universidad de San Martín de Porres.

ORCID: https://orcid.org/0000-0002-2989-2108

Claudia Edith Llontop Diez

Magister en Gestión Cultural, Patrimono y Turismo por la Universidad de San Martín de Porres (Perú). Docente e investigadora de la Escuela Profesional de Turismo y Hotelería de la USMP.

ORCID: https://orcid.org/0000-0001-8627-3760

José Manuel Enrique Marsano Delgado

Magister en Gestión de Empresas Turísticas y Hoteleras por la Universidad de San Martín de Porres (Perú). Docente e investigador de la Escuela Profesional de Turismo y Hotelería de la USMP. Director del Observatorio Turístico del Perú de la Universidad de San Martín de Porres.

ORCID: https://orcid.org/0000-0001-9290-2260

Cristóbal Humprey Noriega Cardó

Doctor en Turismo por la Universidad de San Martín de Porres (Perú). Docente e investigador de la Escuela Profesional de Turismo y Hotelería de la Universidad de San Martín de Porres.

ORCID: https://orcid.org/0000-0003-3143-7865

Sergio Moisés Zapata Acha

Doctor en Ciencias Agronómicas por la Universidad Católica de Lovaina (Bélgica). Docente e investigador de la Escuela Profesional de Turismo y Hotelería de la Universidad de San Martín de Porres.

ORCID: https://orcid.org/0000-0003-1983-4243 